\title{
A MULTI-LAYERED SCAFFOLD OF A CHITOSAN AND GELATIN HYDROGEL SUPPORTED BY A PCL CORE FOR CARDIAC TISSUE ENGINEERING
}

\author{
Seokwon Pok ${ }^{1}$, Jackson D. Myers ${ }^{1}$, Sundararajan V. Madihally ${ }^{2}$, and Jeffrey G. Jacot ${ }^{1,3,{ }^{*}}$ \\ ${ }^{1}$ Department of Bioengineering, Rice University \\ ${ }^{2}$ School of Chemical Engineering, Oklahoma State University \\ ${ }^{3}$ Texas Children's Hospital Division of Congenital Heart Surgery
}

\section{Keywords}

cardiac patch; RVOT; hydrogel; gelatin; chitosan; polycaprolactone; myocardium

\section{INTRODUCTION}

Congenital heart defects are the most common type of birth defects in the U.S [1]. Approximately one in 125 babies born in the United States has a congenital heart defect [2]. One common defect, Tetralogy of Fallot, occurs in approximately 3 to 6 of every 10,000 live births in the U.S. and generally requires surgical placement of a patch or baffle across the right ventricular outflow tract (RVOT) in an area that normally consists of contractile myocardial tissue [3-4]. Currently, knitted polyester (most commonly Dacron) [5], expanded polytetrafluoroethylene (such as Gore-Tex®) [6], and autologous [7] or bovine pericardium [8] are used as cardiac patches for full-thickness repairs of the myocardium to correct congenital cardiac defects. However, these constructs have significant drawbacks, including the inability to grow with the patient's heart, loss of mechanical strength over time, increased risk of thrombosis, limited durability, and inability to regenerate as well as an increased risk of infection and aneurysm [7, 9-11].

\begin{abstract}
A functional full-thickness defect patch should have an ultimate tensile strength exceeding that of mammalian left ventricle ( $0.15 \mathrm{MPa}$ in a canine model [12]). Additionally, the tensile elastic modulus should likely be in the range of current successful materials $(0.6 \mathrm{MPa}$ for Dacron, 0.3 MPa for fixed bovine pericardium, and 0.2 MPa for fixed human pericardium [13-14]) as more elastic materials could form an aneurism and less elastic materials could lead to border areas of very high stress. However, paradoxically, cardiac cells seem to prefer a much softer environment at the cell scale. Previous studies have shown that neonatal rat cardiomyocytes (NRVM) cultured on hydrogels with an elastic modulus nearer to the compressive elastic modulus of native heart tissue, in the range of 10-15 $\mathrm{kPa}$ [15-16], showed in vivo like maturation over a week in culture, with higher contractile force and calcium transients [17]. A similar study using quail chick cardiomyocytes also concluded
\end{abstract}

(C) 2012 Acta Materialia Inc. Published by Elsevier Ltd. All rights reserved.

*Corresponding Author: Jeffrey G. Jacot, Phone : (832)824-5822, Fax : (832)825-5826, jeff.jacot@ rice.edu.

Publisher's Disclaimer: This is a PDF file of an unedited manuscript that has been accepted for publication. As a service to our customers we are providing this early version of the manuscript. The manuscript will undergo copyediting, typesetting, and review of the resulting proof before it is published in its final citable form. Please note that during the production process errors may be discovered which could affect the content, and all legal disclaimers that apply to the journal pertain. 
that cardiomyocytes generate maximal work on gels with elastic modulus near $10 \mathrm{kPa}$ [18]. Additionally, scaffolds should be very porous, with pore sizes on the same order as cardiac cells (about $20-100 \mu \mathrm{m}$ ). Recently, studies have investigated silk fibrin/hyaluronic acid [19], chitosan/fibrin [20], gelatin/poly(glycerol sebacate) [21], and alginate/collagen/ chitosan [22] as patch materials that could be invaded or populated by regenerative cells, and provide better outcomes when placed over cardiac tissue. These materials appear promising for support of infarcted or dilated myocardium, or delivery of regenerative cells and materials. However, many of these approaches lack sufficient tensile strength and pulsatile flow to repair a full-thickness myocardial defect, while many strong biomaterials lack the wall thickness and porosity necessary for loading or migration by a regenerative cell population [23-24].

In this study, we investigated and characterized a multi-layered scaffold manufactured by forming a gelatin-chitosan hydrogel around a self-assembled polycaprolactone (PCL) core for use as a cardiac patch. PCL, a semi-crystalline, linear, aliphatic polyester formed in a ring opening polymerization of caprolactone, is biocompatible, has high tensile strength and has been used in medical devices [25], tissue scaffolds [26-27], and drug delivery systems [28]. Membranes of PCL formed in chloroform can elongate up to $1000 \%$ before breaking. Furthermore, its low melting point $\left(60^{\circ} \mathrm{C}\right)$ allows processing by a variety of techniques. However, PCL surfaces are hydrophobic, preventing absorption of proteins or cell attachment [29]. Previously, we reported a novel process of generating PCL flat matrices in aqueous medium, which decreased the hydrophobic surface properties while maintaining high tensile strength [29].

Gelatin, a denatured form of collagen, is completely bioresorbable, degrades by enzymatic digestion, is biocompatible and can maintain viability of cardiac cells [30-31]. In spite of these advantages, studies have found that scaffolds comprised of gelatin alone are not feasible for use as cardiac patches due to low tensile strength and rapid deformation [32-33]. Furthermore, gelatin scaffolds are susceptible to rapid degradation, though composite scaffolds of gelatin and chitosan are structurally stable in cell culture media [34]. Chitosan has excellent biocompatibility, and its enzymatic degradation rate depends on its degree of deacetylation (DD) and can be tuned to the application. Chitosan has been widely investigated in biomedical applications including wound dressing [35], drug delivery systems [36-37] and cardiac tissue engineering [38]. Porous chitosan structures can be formed by freeze-drying, with the pore size and porosity controlled as a function of freezing temperature [39-40]. However, cardiomyocytes do not attach and survive on pure chitosan scaffolds [20]. Furthermore, the chitosan solution has the same charge as self-assembled PCL scaffolds, preventing ionic binding of chitosan to a PCL surface [29].

In this study, we designed a composite cardiac patch intended for repair of a full-thickness myocardial defect. This patch contains a thin, self-assembled PCL core, intended to provide surgeons the ability to handle, cut and suture the material and to provide sufficient tensile strength to function in the ventricular wall. Surrounding the core is a porous, biocompatible gelatin-chitosan hydrogel that allows for cell loading or migration and provides a scaffold for cardiac cell growth and maturation. The effect of PCL molecular weight (number average; $\mathrm{Mn}$ ) on the surface morphology, degradation kinetics and tensile mechanical properties and the effect of the ratio of gelatin to chitosan in the hydrogel on the compressive mechanics, porosity and liquid content were measured. Next, the adherence of the PCL core and hydrogel was tested and the suture strength was measured and compared to current materials. Finally, neonatal rat cardiomyocytes were used to investigate cardiac cell adhesion, migration and morphology. 


\section{MATERIALS AND METHODS}

\subsection{Preparing solutions and forming blends}

PCL solutions of $10 \%(w t / v)$ in glacial acetic acid (Pharmco Products Inc., Brookfield, CN) were prepared for each number average molecular weight (Mn) PCL, $80 \mathrm{kDa}, 47 \mathrm{kDa}$, and $10 \mathrm{kDa}$ Mn(Sigma Aldrich, St. Louis, MO). Blended solutions were also prepared by mixing equal volumes of individual solutions of pure $80 \mathrm{kDa}, 47 \mathrm{kDa}$, and $10 \mathrm{kDa} \mathrm{Mn}$. Chitosan, low molecular weight (Sigma Aldrich, St. Louis, MO), solutions (2\% w/v) were prepared in distilled water with $0.5 \mathrm{M}$ acetic acid. Gelatin, type A (Sigma Aldrich, St. Louis, MO), solutions $(2 \% \mathrm{w} / \mathrm{v})$ were prepared in distilled water. Chitosan and gelatin solutions were mixed with different ratios (1:3,1:1, and $3: 1$; gelatin:chitosan) and emulsified using sonicator (Fisher Scientific FS20D) for $30 \mathrm{~min}$. All solutions were used within 2 days.

\subsection{PCL scaffold and multi-layers formation}

PCL matrices were made using a previously described procedure [29] with minor modifications. In brief, solutions of pure $80 \mathrm{kDa}$ and $47 \mathrm{kDa}$ PCL and mixtures of $80+47$ $\mathrm{kDa}, 80+10 \mathrm{KDa}$ and $80+47+10 \mathrm{kDa}$ PCL $(100 \mu \mathrm{l})$ were pipetted into a custom-made Teflon mold containing $2 \mathrm{~mL}$ of water and formed solid scaffolds with controlled diameters $(17 \mathrm{~mm})$. Although matrices formed spontaneously on contact with water, they were undisturbed for 10 minutes to allow the process of matrix formation to complete. Matrices were submersed in absolute ethanol for one hour to remove any remaining acetic acid. These matrices were used for mechanical testing, degradation and porosity analysis.

Self-assembled PCL scaffolds containing $80 \mathrm{kDa}$ and $10 \mathrm{kDa}$ PCL were sandwiched between emulsified solutions of gelatin and chitosan by lyophilization. In brief, $300 \mu \mathrm{L}$ solutions were poured into custom-made Teflon moulds. Then PCL matrices were laid down on the solutions, and an additional $300 \mu \mathrm{L}$ was poured onto the surfaces. These samples were left at room temperature for 2 hours and then incubated in a box with dry ice. Frozen samples were lyophilized at $-50^{\circ} \mathrm{C}$ for 24 hours. The multi-layered scaffolds were submersed in absolute ethanol overnight. These multi-layered scaffolds were used for surface morphology analysis, mechanical tests, suture strength tests and cellular activity tests. Some of the hydrogels were cut using a surgical blade for cross-sectional imaging of the multi-layered structure.

\subsection{Number average molecular weight (Mn) measurement of PCL matrices}

Gel-permeation chromatography was used in order to measure number average molecular weight (Mn) and polydispersity index of the PCL contained in the crystallized matrices. Formed PCL matrices were dissolved in mobile phase of chloroform. Then Mn and polydispersity index were analyzed relative to poly(styrene) standards using a Phenogel ${ }^{\mathrm{TM}}$ column (Phenomenex, Torrance, CA) and a refractive index detector.

\subsection{Degradation characterization of PCL matrices}

Degradation rates of PCL matrices were analyzed using a previously described procedure with minor modifications [41]. In brief, $15 \times 15 \mathrm{~mm}$ samples were cut from each matrix, washed with deionized water, sterilized in $70 \%$ ethanol for one hour and washed thoroughly in sterile Krebs Henseleit buffer solution (in mM: $\mathrm{NaCl} 119 ; \mathrm{KCl} 4.7 ; \mathrm{NaHCO}_{3} 25 ; \mathrm{CaCl}_{2}$ 2.5; $\mathrm{KH}_{2} \mathrm{PO}_{4} 1.2 ; \mathrm{MgSO}_{4} 1.2$ ) prior to incubating in $10 \mathrm{~mL}$ Krebs Henseleit buffer solution $(\mathrm{pH}=7.4)$. Samples were placed in $20-\mathrm{mL}$ vials with a $15-\mathrm{mm}$ diameter hole drilled in the caps and covered on the inside with $0.45 \mathrm{~m}$ filters. Incubation was carried out in an incubator maintained at $37^{\circ} \mathrm{C}$ and $5 \% \mathrm{CO}_{2} / 95 \%$ air. During the incubation, the $\mathrm{pH}$ of the effluent was maintained at 7.4 by replacing the buffer solution once every six days, and never dropped below 7.1. 
At ten-day intervals, three samples per group were retrieved and weighed. Digital images of these samples were also taken to assess dimensional changes. Collected samples were washed with deionized water, dehydrated using absolute alcohol and briefly dried in a vacuum desiccator at ambient conditions prior to final weight determination. Samples were also analyzed by SEM to characterize structural changes.

\subsection{Mechanical testing}

Tensile testing was performed using a previously described method [29]. In brief, $30 \times 10$ $\mathrm{mm}$ rectangular strips were cut from each scaffold, strained to the breaking point at a constant crosshead speed of $10 \mathrm{~mm} / \mathrm{min}$ using an INSTRON 5842 (INSTRON Inc., Canton, MA) and analyzed for break stress and strain using the software package Merlin (INSTRON Inc.). Samples were tested at $37^{\circ} \mathrm{C}$ in $\mathrm{PBS}(\mathrm{pH}=7.4)$ using a custom-built environmental chamber. The elastic modulus was calculated from the slope of the linear portion $(0.1 \%$ to $5 \%$ strain range) of the stress-strain curve. To measure the thickness of the matrices, digital micrographs were obtained at various locations using an inverted microscope (Nikon TE2000U, Melville, NY) equipped with a CCD camera. These images were quantified for the thickness using image analysis software Sigma Scan Pro (SPSS Science, Chicago, IL), calibrated using a micrograph of a hemocytometer at the same magnification. Four to five images were obtained per sample with at least ten points per image. The calculated minimum thicknesses were used to determine the stress values in each sample.

The compressive strength of the multi-layered hydrogels was also measured to characterize the effect of different ratios of gelatin and chitosan on the compressive modulus [42]. Rehydrated samples $(n=3-5)$ were placed in stainless steel platens in a Bose-Enduratec ELF3200 (Bose Electroforce, Eden Prairie, MN) and compressed up to 3\% strain $(\sim 100 \mu \mathrm{m})$ at $1 \mathrm{~mm} / \mathrm{s}$ of load speed. The load displacement data was converted into compression strength.

\subsection{Microstructure analysis}

All samples were incubated in absolute ethanol for one hour and allowed to dry overnight in a vacuum desiccators at room temperature. Dry matrices were attached to aluminum stubs with carbon paint and sputter-coated with gold for one minute. Surface architecture of the scaffolds was analyzed using a scanning electron microscope (JEOL 6360, Jeol USA Inc., Peabody, MA) at an accelerating voltage of $15 \mathrm{kV}$. Images were analyzed for the average pore size ( $\mathrm{n}=20$ on 3 different samples) using ImageJ.

The ability of the multi-layered scaffolds to absorb water was measured by determining volumes of dry and wet samples. Total volumes of dry scaffolds $\left(\mathrm{V}_{t}\right)$ were measured using an analytical balance. The scaffolds were then submerged in a graduated cylinder containing absolute ethanol. Scaffolds were removed from the cylinder and the remaining amount of liquid was recorded to determine the uptake of alcohol by the scaffold $\left(\mathrm{V}_{\mathrm{u}}\right)$. The liquid content was calculated as

$$
\text { Liquid Content }(\%)=\frac{\mathrm{V}_{\mathrm{t}}-\mathrm{V}_{\mathrm{u}}}{\mathrm{V}_{\mathrm{t}}} \times 100(\%)
$$

\subsection{Suture tension analysis}

The ultimate suture tension of multi-layered hydrogels was measured and compared with estimated left ventricular stitch tension. In brief, $15 \times 7 \mathrm{~mm}$ samples were cut from each multilayered hydrogel, and a $2 \mathrm{~mm}$ suture was applied with 6-0 polypropylene suture thread. 
The ultimate tensile forces of the sutured samples were measured by uniaxial force test using Bose-Enduratec ELF3200 (Bose Electroforce, Eden Prairie, MN)., The expected maximum stitch tension of a patch implanted in a human left ventricle was calculated as

$$
\text { Tension }(\mathrm{N})=p_{w} \times \delta_{w} \times d_{s}
$$

Where $p_{W}$ is the left ventricular end-systolic pressure $(138 \pm 21 \mathrm{mmHg})$ [43], $\delta_{W}$ is the left ventricular end-systolic wall thickness $(13.4 \pm 2.1 \mathrm{~mm})$ [44], and $d_{S}$ is the distance between sutures $(2 \mathrm{~mm})$.

\subsection{Endotoxin measurement}

Endotoxin in multi-layered composite hydrogels were measured using a PYROGENTTM Plus Gel Clot limulus amebocyte lysate (LAL) kit that had a sensitivity of $0.25 \mathrm{EU} / \mathrm{mL}$ (Lonza, MD), using the manufacturer's procedure. Hydrogels were submerged in an endotoxin-free test tube with LAL reagent water to wash out endotoxin from the hydrogels overnight. $250 \mu \mathrm{L}$ of each sample was pipetted into the LAL test kit, then incubated in a water bath at $37^{\circ} \mathrm{C}$ for 1 hour. Endotoxin-free water and E. Coli was used as a negative and positive control respectively. After 1-hour incubation, tubes were flipped $180^{\circ}$. A firm clot in the bottom of the tube indicates a positive reaction.

\subsection{Neonatal rat ventricular myocyte isolation and culture}

All studies involving experimental animals were approved by the Institutional Animal Care and Use Committees of both Rice University and Baylor College of Medicine. Neonatal rat ventricular myocytes (NRVM) were isolated from Sprague-Dawley rat hearts as described previously with minor modification [17]. Briefly, 1 to 3 day old Sprague-Dawley rats were anesthetized with isoflurane, decapitated and the hearts were removed. Blood vessels and atria were trimmed, leaving only the ventricles. Ventricular cardiomyocytes were isolated using enzymatic digestion with an isolation kit (Cellutron, Highland Park, NJ). Isolated cells were pre-plated in petri dishes for 2 hours to remove fibroblasts and endothelial cells. Unattached cells at $5 * 10^{5}$ cells in $2 \mathrm{~mL}$ high-serum plating media (Dulbecco modified Eagle media, $17 \%$ M199, 10\% horse serum, 5\% foetal bovine serum, $100 \mathrm{U} / \mathrm{mL}$ penicillin and 50 $\mathrm{mg} / \mathrm{mL}$ streptomycin) were seeded onto each multi-layered scaffold. After 12-24 hours, cell seeded samples were transferred to a low serum media. (Dulbecco modified Eagle media, $18.5 \% \mathrm{M} 199,5 \%$ horse serum, $1 \%$ foetal bovine serum, and antibiotics). Cell cultures were maintained at $37^{\circ} \mathrm{C}$ and $5 \% \mathrm{CO}_{2} / 95 \%$ air and fresh maintenance media was added every 2 days. All culture media was purchased from Invitrogen (Carlsbad, CA) and serum was purchased from PAA Laboratories (Ontario, Canada).

\subsection{Cellular viability and migration analysis}

In order to quantify cardiomyocyte viability on multi-layered scaffolds, $5^{*} 10^{5}$ cells in $2 \mathrm{~mL}$ media were seeded onto hydrogels and cultured for 4 to 14 days, maintained in 5\% $\mathrm{CO}_{2} / 95 \%$ air at $37^{\circ} \mathrm{C}$ with medium changes every 48 hours. Cells were then washed in cold $\left(4^{\circ} \mathrm{C}\right) \mathrm{PBS}$ and fixed in $4 \%$ paraformaldehyde (Electron Microscopy Sciences) for 20 minutes at $4{ }^{\circ} \mathrm{C}$. Cells were washed with PBS and made permeable with $0.5 \%$ Triton X100 (Sigma). Cells were again washed in PBS and stained with Alexa Fluor ${ }^{\circledR} 488$ Phalloidin (Invitrogen Corp., Eugene, OR) at a 1:1000 dilution in 1\% bovine serum albumin (BSA, Gemini Bioproducts) overnight at $4^{\circ} \mathrm{C}$. Cells were then counterstained with DAPIcontaining Vecta Shield (Vector, Burlingame, CA). Images were obtained using a DMI 6000B (Lieca Microsystems, Bannockburn, IL) fluorescence microscope to analyze cell adhesion and morphology. Primary and secondary antibodies of cardiac cell makers were 
also used to characterize NRVM morphologies. Monoclonal Anti-a-actinin (1:400, SigmaAldrich, MO) and connexion 43/GJA1 (1:400, Abcam, MA) were used to visualize sarcomeres and gap junctions respectively. Antibodies were used at 1:400 dilution in 1\% BSA and incubated for 1 hour at room temperature. Secondary antibodies of DyLightTM 488-conjugated Goat Anti-Mouse (1:400, JacksonIR, PA) and 549-conjugated Goat AntiRabbit were used at 1:400 dilution in 1\% BSA and incubated for 30 minutes at room temperature followed by four $1 \%$ BSA washes. Additionally, NRVM were cultured on multilayered scaffolds for 7 days and stained with Live/Dead assay reagents (Invitrogen Corp., Eugene, OR) to determine cell viability.

For the analysis of cell migration, $1 * 10^{6}$ cells $/ 2 \mathrm{~mL}$ media were cultured on the surface of multi-layered scaffolds for 7 days and fixed in paraformaldehyde using the above procedure. Scaffolds were then fully dehydrated and embedded in paraffin for sectioning to evaluate cell migration into the scaffold. Sectioned samples $(10 \mu \mathrm{m}$ thick) were stained with haematoxylin and eosin (H\&E; Leica Biosystems, Richmond, IL) to detect nuclei (black) and protein (red) respectively. Images were taken using a Nikon-Elements E800.

\subsection{Statistical analysis}

Cell culture experiments were repeated three or more times with quadruplicate samples. Tensile testing was repeated four or more times. Specific repeat numbers are noted in figure captions. Results are reported as mean \pm standard deviation. Significant differences between groups were evaluated using a one way analysis of variance (ANOVA) with $95 \%$ or $99 \%$ confidence interval, then paired differences were tested with a post-hoc student $t$-test with a Bonferroni-Dunn correction for multiple comparisons. When $\mathrm{p}<0.05$, the differences were considered to be statistically significant.

\section{RESULTS}

\subsection{Macroscopic properties of PCL scaffolds}

Solutions of pure 80 and $47 \mathrm{kDa}$ and mixtures of $80+10 \mathrm{kDa}$ and $80+47+10 \mathrm{kDa}$ PCL readily formed solid, stable scaffolds on contact with the water bath. However, solutions of $10 \mathrm{kDa}$ PCL and mixtures of $47+10 \mathrm{kDa}$ PCL did not produce a stable structure despite precipitation, suggesting that the Mn of PCL plays a role in the matrix formation. Furthermore, when higher Mn PCL solutions were stored for more than four days, no solid scaffold formed, possibly due to acid hydrolyses of the polymer. Hence, all solutions were freshly prepared. No further testing was done with $10 \mathrm{kDa}$ PCL and mixtures of $47 \mathrm{kDa}$ and 10kDa PCL solutions.

Liquid chromatography analysis verified general molecular weight ranges, though measured average Mn was slightly lower than product-indicated for pure PCL matrices (Figure 1). Analysis also indicated two distinct Mn peaks at distinct retention times in the $80+10 \mathrm{kDa}$ blended matrix with nearly equal areas, verifying that the $10 \mathrm{kDa}$ PCL was fully incorporated into the scaffold at approximately $50 \%$.

\subsection{Surface morphology of PCL scaffolds}

PCL matrices were crystalized on the surface of a water bath, and thus had one surface exposed to water and one exposed to air during formation. In order to test whether the surface exposed to the air (referred to as the top surface) differed in roughness compared to the surface exposed to water (referred to as the bottom surface), we evaluated the matrices using SEM. The top and bottom sides of the scaffolds had significant differences in surface structure. The top side of all scaffolds showed a porous structure, while the bottom side had rough surfaces with significantly fewer pores. In all subsequent experiments, samples were 
flipped thrice consecutively, before matrix formation was completed. This resulted in equivalent surface structure and roughness (data are not shown)

PCL matrices containing pure 80 and $47 \mathrm{kDa}$ PCL had no significant difference in surface morphology, while 80:10 kDa blended matrices had a significantly increased pore size $(80+10 \mathrm{kDa}: 21.7 \pm 1.0 \mu \mathrm{m})$ compared to other samples $(80 \mathrm{kDa}: 3.25 \pm 0.96,47 \mathrm{kDa}$ : $3.62 \pm 1.15,80+47+10: 6.90 \pm 2.16 \mu \mathrm{m} ; \mathrm{p}<0.05, \mathrm{n}=20$; Figure 2. E), with perforations on the surface and microdomain-like indentations (Figure 2. A-D).

\subsection{Effect of PCL Mn on degradation rate}

Scaffolds were incubated in a Krebs Henseleit buffer solution for 50 days to quantify the effect of varying PCL molecular weights on the degradation rate. The presence of low $\mathrm{Mn}$ PCL increased the degradation rate (Figure 3. A). The 80+10 kDa PCL matrices had 10\% weight loss after 50 days incubation. There was no significant difference in the weight of pure 80 and $47 \mathrm{kDa}$ PCL scaffolds, confirming that the weight loss was primarily due to degradation of the $10 \mathrm{kDa}$ PCL. This suggests polymers were present individually in the matrices without combining.

When dimensions of the scaffolds were analyzed, no significant change in width or length was observed. All scaffolds except for the $80+10 \mathrm{kDa}$ PCL blend appeared intact at the end of the 50-day study period (Figure 3. B). The $80+10 \mathrm{kDa}$ scaffold ruptured at 50 days. Furthermore, the $80+10 \mathrm{kDa}$ matrix also showed an increase in number of holes in the matrix at 30 days, possibly corresponding to the microdomains observed by SEM.

To understand the changes in surface architecture during degradation, 80+10 kDa scaffolds were analyzed by SEM after 10, 30 and 50 days in Krebs-Henseleit buffer, since only these samples showed a significant degradation rate. Electron micrographs showed no obvious alteration of the surface architecture of the scaffold during the first ten days (Figure 3. C). Generally, samples retrieved after thirty days of incubation had an increase of the number of pores ( $8 \pm 6$ for 10 days and $59 \pm 15$ for 30 days; $n=3, p<0.05$ ) (Figure 3. C). Images of samples retrieved after fifty days showed that some parts of scaffolds completely degraded in the buffer solution. This suggests that self-assembled scaffolds of high Mn PCL are stable despite dissolution in acetic acid. Degradation was localized to the regions containing 10 $\mathrm{kDa}$ PCL.

Because $80+10 \mathrm{kDa}$ blended matrices had the greatest pore size and surface roughness, allowing for adhesion with the gelatin-chitosan hydrogel, all multi-layered scaffold studies were performed with $80+10 \mathrm{kDa}$ blended PCL cores.

\subsection{Mechanical properties of PCL scaffolds and multi-layered hydrogels}

Tensile properties of multi-layered and PCL only matrices were assessed under physiologic conditions. The tensile elastic (Young's) modulus of $80 \mathrm{kDa}$ PCL matrix was higher than the $47 \mathrm{kDa}$ PCL matrix. However, the presence of $10 \mathrm{kDa}$ PCL caused a significant increase in stiffness and reduction of ultimate tensile stress compared to higher Mn PCL matrices (*; $\mathrm{p}<0.05 ; \mathrm{n}=5$ ) (Figure 4 . A,C). Ultimate tensile stress was positively correlated with molecular weight, and matrices comprised of a single Mn PCL had significantly higher ultimate tensile stresses than blended Mn matrices (80 kDa: $3.9 \pm 0.34,47 \mathrm{kDa}: 3.2 \pm 0.26$, $80+10 \mathrm{kDa}: 1.8 \pm 0.14,80+47+10: 2.0 \pm 0.06 \mathrm{MPa} ; \mathrm{p}<0.05, \mathrm{n}=5$; Figure 4. B). Note that the ultimate tensile strain was greatly reduced by an order of magnitude by the addition of 10 $\mathrm{kDa}$ PCL, though the yield strain, or the point where the material begins plastic deformation, is in the same range for all blends. 
In order to evaluate the effect of the gelatin-chitosan gel layers in a multi-layered scaffold on the tensile strength needed to function as a full thickness defect patch in the high stress ventricular wall, the tensile strength, and tensile elastic modulus of multi-layered scaffolds were measured under hydrated conditions. However, most of this tensile strength is provided by the PCL core, and cells loaded in the hydrogel layers experience a much softer environment. In order to fully characterize the hydrogel mechanical environment, the compressive modulus of the scaffold was measured. The ultimate tensile strength and tensile elastic modulus and of multilayered hydrogel scaffolds with gelatin-chitosan and $80+10 \mathrm{kDa}$ PCL were not significantly different than those of the core $80+10 \mathrm{kDa}$ PCL matrices (Tensile strength $1.80 \pm 0.14 \mathrm{MPa}$ vs. $1.62 \pm 0.48 \mathrm{MPa}, \mathrm{p}=0.499, \mathrm{n}=4$; elastic modulus: $315 \pm 81$ $\mathrm{kPa}$ vs. $249 \pm 29 \mathrm{kPa}, \mathrm{p}=0.178, \mathrm{n}=4$ ) (Figure 4 . A-C). However, the compressive modulus of the multi-layered scaffold was two orders of magnitude lower than the tensile modulus, and increased with increasing gelatin concentration $(3.5 \pm 1.1 \mathrm{kPa}$ of $25 \%$ gelatin; $13.1 \pm 1.6$ $\mathrm{kDa}$ of $50 \% ; 18.4 \pm 2.1$ of $75 \%$; $\mathrm{p}<0.001, \mathrm{n}=4$ ) (Figure 4. D). No delamination of the gelatinchitosan hydrogel and PCL core was observed in any tensile or compression testing.

\subsection{Morphological characteristics of multi-layered scaffolds}

Electron micrographs show that the gelatin-chitosan hydrogel attached to the both sides of 80:10 kDa PCL matrix and adhered by penetrating through perforations in the PCL matrix (Figure 5. B). SEM analysis showed that the number of pores on the surface was increased with an increase in the amount of gelatin (Figure 5. A-D). Scaffolds of 50\% or higher gelatin had a hive-like structure and eliptical pores. All samples formed three-dimensional (3-D) porous structures after lyophilization (Figure 5. E-H). However, pure chitosan and hydrogels with $25 \%$ gelatin had highly variable pore sizes with larger pores in the side of scaffolds, whereas hydrogels with 50 and $75 \%$ gelatin had a uniformly distributed porous structure. In addition, only $75 \%$ gelatin samples showed a compressed thickness $(\sim 2.3 \mathrm{~mm})$ compared to other samples ( $3 \mathrm{~mm}$ for 0,25 and $50 \%$ gelatin)

\subsection{Suturability of multi-layered scaffolds}

Multi-layered scaffolds composed of an 80+10 kDa PCL core sandwiched in a gelatinchitosan composite hydrogel were manufactured in disks of approximately $3 \mathrm{~cm}$ in height and $17 \mathrm{~cm}$ in diameter (Figure 6. A). No delamination was observed when scaffolds of $80+10 \mathrm{kDa}$ PCL coated with gelatin-chitosan hydrogel were submersed in ethanol and incubated in PBS for mechanical testing or in cell culturing media for 7 days, confirming secure attachment between the two materials. The adhesion was strong enough that the gelatin-chitosan hydrogel failed before delamination of the materials, preventing the ability to test adhesion strength.

The ultimate suture force of multi-layered hydrogels was measured and compared with computed force on sutures through a full thickness patch in a human left ventricle (LV) (see Methods section for calculation). The ultimate suture force of the multi-layered scaffold was significantly higher than the estimated LV suture force $(1.84 \pm 0.20 \mathrm{~N}$ vs. $0.61 \pm 0.18$; $\mathrm{p}<0.001, \mathrm{n}=5$ ) (Figure 6. C).

\subsection{Liquid content of multi-layered scaffolds}

The liquid content and porosity of the cross-sectional area significantly decreased at higher amounts of gelatin (Figure 7. A); the pure chitosan sample absorbed $\sim 80 \%$ of liquid volume in the scaffold and had $\sim 75 \%$ cross sectional porosity, while the $75 \%$ gelatin sample absorbed $\sim 60 \%$ and had $\sim 55 \%$ cross sectional porosity. Pure chitosan, with lower surface porosity, had larger mean pore diameters in both the major and minor axes compared to pore diameters of scaffolds formed with $25 \%$ gelatin. However, the mean pore sizes increased significantly with increasing gelatin concentration $(64.7 \pm 14.3 \mu \mathrm{m}$ of $25 \%$ vs. $83.4 \pm 15.4 \mu \mathrm{m}$ 
of 50\%; $\mathrm{p}<0.05, \mathrm{n}=8$ ) (Figure 7. B). There was no significant difference between $50 \%$ and $75 \%$ gelatin containing scaffolds.

\subsection{Endotoxin content in multi-layered scaffolds}

None of these formulations of gelatin-chitosan hydrogels were positive for endotoxin contamination per a test kit with $0.25 \mathrm{EU} / \mathrm{mL}$ sensitivity ( $\mathrm{n}=4$ for each ratio). The U.S. Food and Drug Administration (FDA) regulations set a limit of $0.5 \mathrm{EU} / \mathrm{mL}$ of endotoxin in a medical device.

\subsection{Ventricular myocyte adhesion}

Cell adhesion of NRVM to self-assembled PCL scaffolds or multi-layered scaffold of gelatin-chitosan coated PCL was evaluated by immunostaining after 7 days in culture. Substantial deformation was observed in $75 \%$ gelatin- $25 \%$ chitosan scaffolds, though all other scaffolds maintained structural stability. Significantly more cells were attached to the scaffolds of $25 \%$ gelatin- $75 \%$ chitosan and $50 \%$ gelatin- $50 \%$ chitosan compared to $75 \%$ gelatin- $25 \%$ chitosan or uncoated scaffolds $\left(\sim 57\right.$ cells $/ 0.1 \mathrm{~mm}^{2}$ for 25 and $50 \%$ vs. $\sim 10$ cells/ $0.1 \mathrm{~mm}^{2}$ for $75 \%$ and uncoated PCL; $\mathrm{p}<0.001, \mathrm{n}=5$; Figure 8 . A). Further, NRMV on the $50 \%$ gelatin-50\% chitosan samples formed interconnected cell sheets (Figure 8. B) and had strong, spontaneous beating that was not repeatably observed in NRVM on other gelatinchitosan ratios (Supplemental data: Movie 1).

\subsection{Cell morphology}

Cell morphology of NRVM was also evaluated by immunostaining after 4, 7, and 10 days of culture on multi-layered hydrogels (Figure 9). After 4 days, all samples showed scattered cell attachment, and cell sizes were below $100 \mu \mathrm{m}^{2}$ in all samples. After 7 days, NRVM on 25 and $50 \%$ gelatin scaffolds were well spread and connected to each other whereas NRVM on the $75 \%$ gelatin scaffold showed no interconnection. After 10 days in culture, cells were interconnected and integrated though the scaffolds with showing sarcomeres and gap junctions, except on $75 \%$ gelatin samples. The $75 \%$ gelatin- $25 \%$ chitosan scaffolds showed poor integration of cells, due to the high deformation of the scaffold. Hence the $75 \%$ gelatin sample was excluded from further analysis.

Live/dead staining revealed high cell viability ( $\sim 80 \%)$ of NRVM plated on multi-layered scaffolds with $25 \%$ and $50 \%$ gelatin which is similar to the viability of NRVM plated on tissue culture plastics $(\sim 83 \%)$ (Figure 10).

\subsection{NRVM migration in 3-D multi-layered scaffolds}

Histological analysis and immunocytology staining found that NRMV infiltrated and colonized multi-layered scaffolds after 10 days culture (Figure 11. A-B). The 50\% gelatin-50\% chitosan scaffolds, which had higher mean pore size, had more cells in the scaffold and showed high NRMV interconnectivity compared to the 25\% gelatin-75\% chitosan scaffolds (Figure 11. C-D). The 50\% gelatin-50\% chitosan scaffold was cut and imaged in a cross-sectional view, and revealed that the number of migrating cells decreased and the number of dead cells increased with depth into the scaffold (Figure 11. E).

\section{DISCUSSION}

In this study, we found that the tensile strength and degradation rate of PCL matrices were dependent on the molecular weight of the PCL, with lower molecular weight and blends of different weight PCL having lower tensile strength and faster degradation. However, the tensile strengths of all tested formulations were greater than $1.89 \pm 0.14 \mathrm{MPa}$ and are sufficient for support of a full-thickness ventricular defect. 
A blend of $10 \mathrm{kDa}$ Mn PCL with $80 \mathrm{kDa}$ Mn PCL formed matrices with microdomain-like indentations, which allowed for adhesion to gelatin-chitosan hydrogels, and this formulation was thus used for all multi-layer scaffolds. Using the $80+10 \mathrm{kDa}$ PCL blend, there was no need to perforate the self-assembled PCL matrix to ensure adhesion, unlike in one previously reported PLGA-based composite [45]. Because the $10 \mathrm{kDa}$ PCL alone did not form solid matrices, similar to previous reported results [46], we considered the possibility that the $10 \mathrm{kDa}$ PCL washed out of the matrix, leaving behind the large pore structures and rough surface. However, the liquid chromatography analysis verified that the formed structures contained both molecular weights, in approximately equal amounts. Thus, the observed microdomains could be an effect of the differences in crystallinity between the two Mn solutions, and likely causes the higher degradation rate in these blended PCL matrices [47]. Interestingly, the addition of $10 \mathrm{kDa}$ PCL to $80 \mathrm{kDa}$ PCL resulted in an increase in elastic modulus, even though, in pure PCL solutions, lower molecular weight correlated with a lower elastic modulus. This result of blended Mn PCL films having higher elastic modulus, and lower ultimate tensile strength has been noted previously by Jones et al. and is attributed to the semi-crystalline nature of PCL. Lower Mn PCL is more likely to form crystalline regions in the largely amorphous high Mn PCL structure, making the resulting material more brittle [48]. The increase in material brittleness is also apparent in the lack of plastic deformation in the materials containing the low Mn PCL. Though all materials have similar yield points, non-blended, high Mn PCL matrices could be stretched up to $300 \%$ strain before breaking. In a cardiac patch application, however, plastic deformation would be very undesirable and would likely lead to aneurismal patch deformation and necessitate reoperation and replacement. Thus the ultimate tensile strain and yield point should all be higher than the maximal stress on the patch.

Coating an $80+10 \mathrm{kDa}$ PCL matrix core with a gelatin-chitosan hydrogel to create a multilayered scaffold did not alter the macroscopic tensile modulus or ultimate tensile strength. Scaffolds also had sufficient suture retention strength $(1.84 \pm 0.21 \mathrm{~N})$ for repair of a fullthickness left ventricular defects (Supplemental data: Movie 2) compared to suture retention strength of the porcine left ventricle $(0.61 \pm 0.21 \mathrm{~N})$ and materials currently used clinically such as bovine pericardium matrix $(0.71 \pm 0.23 \mathrm{~N})$, collagen-impregnated polyethylene terephthalate $(0.76 \pm 0.14 \mathrm{~N})$, and expanded polytetrafluoroethylene $(4.69 \pm 0.14 \mathrm{~N})[12,49]$. Interestingly, the porosity of the hydrogel portion, as well as the water content, decreased as the percentage of gelatin increased. This is initially surprising, because gelatin is typically more hydrophilic than chitosan, and previous studies have shown increasing permeability and water content with increasing gelatin concentration in gelatin-chitosan hydrogels [5051]. However, previous studies using similar methods of processing gelatin-chitosan composite gels have noted that, in some circumstances, the incorporation of gelatin decreases the water content, likely due to strong interactions between gelatin and chitosan that can displace sites of hydrogen binding with water [52].

We found that cell adhesion, spreading and spontaneous beating all increased on multilayered gelatin-chitosan hydrogel scaffolds with a PCL core compared to PCL alone. This effect is likely due to the lack of cell binding domains in PCL [29]. The multi-layered scaffolds with a 50\% gelatin : $50 \%$ chitosan (v:v) blend had the highest cell attachment, spreading and interconnectivity, and formed spontaneously beating tissue constructs. Interestingly, cell attachment decreased on hydrogels with $75 \%$ gelatin, compared to hydrogels with lower concentrations (50\% and 25\%), despite the predicted increase in biocompatibility and binding sites with increased collagen. The improved attachment, spreading and interconnectivity on hydrogels of $50 \%$ gelatin was likely due in part to the elliptical, homogeneously sized pores observed in those scaffolds. Additionally, multilayered scaffolds with $50 \%$ gelatin-50\% chitosan supported by an $80+10$ kDa PCL matrix had a compressive modulus similar to native heart matrix [15-16]. 
We feel that this patch design can support cells, either plated before implantation or invading from host vasculature, and function as a full-thickness defect myocardial patch. Future research will involve testing this multi-layered scaffold in vivo in a full thickness defect right ventricle patch in a rat model.

\section{CONCLUSION}

Collectively, the results of this study demonstrate that a multi-layered scaffold of PCL sandwiched in a gelatin-chitosan hydrogel is biodegradable, has sufficient mechanical strength, and can maintain cardiomyocytes viability for use of cardiac patch application. The best results in terms of cell spreading and viability and scaffold integrity resulted from a PCL core with equal parts of $10 \mathrm{kPa}$ and $80 \mathrm{kPa}$ PCL sandwiched in a blend of 50\% gelatin-50\% chitosan. In summary, this multi-layered hydrogel shows significant potential for use of cardiac patch to repair congenital cardiac defects.

\section{Supplementary Material}

Refer to Web version on PubMed Central for supplementary material.

\section{Acknowledgments}

The research was supported by Texas Children's Hospital and grant 1R21HL110330 (to JGJ) from the National Institutes of Health. The authors would like to thank Dr. Jennifer West, Dr. Antonios Mikos and Dr. K. Jane Grande-Allen in the Department of Bioengineering at Rice University for the use of and assistance with the lyophilizer, mechanical testing machine and liquid chromatography.

\section{References}

1. Roger VL, et al. Heart Disease and Stroke Statistics-2011 Update. Circulation. 2011; 123:e18e209. [PubMed: 21160056]

2. Baldwin JT, Borovetz HS, Duncan BW, Gartner MJ, Jarvik RK, Weiss WJ, et al. The National Heart, Lung, and Blood Institute Pediatric Circulatory Support Program. Circulation. 2006; 113:147-55. [PubMed: 16391168]

3. Jenkins KJ, Correa A, Feinstein JA, Botto L, Britt AE, Daniels SR, et al. Noninherited Risk Factors and Congenital Cardiovascular Defects: Current Knowledge. Circulation. 2007; 115:2995-3014. [PubMed: 17519397]

4. Reller MD, Strickland MJ, Riehle-Colarusso T, Mahle WT, Correa A. Prevalence of congenital heart defects in metropolitan Atlanta, 1998-2005. J Pediatr. 2008; 153:807-13. [PubMed: 18657826]

5. Kochupura PV, Azeloglu EU, Kelly DJ, Doronin SV, Badylak SF, Krukenkamp IB, et al. Tissueengineered myocardial patch derived from extracellular matrix provides regional mechanical function. Circulation. 2005; 112:I144-I9. [PubMed: 16159807]

6. Afrasiabi A, Samadi M, Montazergaem H. Valved patch for ventricular septal defect with pulmonary arterial hypertension. Asian cardiovascular \& thoracic annals. 2006; 14:501-4. [PubMed: 17130327]

7. Tudorache I, Kostin S, Meyer T, Teebken O, Bara C, Hilfiker A, et al. Viable vascularized autologous patch for transmural myocardial reconstruction. Eur J Cardio-Thorac Surg. 2009; 36:306-11.

8. Maizato MJS, Pires MD, Canzian M, Higa OZ, Pitombo RNM, Leirner AA. Histological evaluation of biocompatibility of lyophilized bovine pericardium implanted subcutaneously in rats. Artif Organs. 2008; 32:268-71. [PubMed: 18370939]

9. Mirensky TL, Breuer CK. The development of tissue-engineered grafts for reconstructive cardiothoracic surgical applications. Pediatr Res. 2008; 63:559-68. [PubMed: 18427302]

10. Santibanez-Salgado JA, Olmos-Zuniga JR, Perez-Lopez M, Aboitiz-Rivera C, Gaxiola-Gaxiola M, Jasso-Victoria R, et al. LYOPHILIZED GLUTARALDEHYDE-PRESERVED BOVINE 
PERICARDIUM FOR EXPERIMENTAL ATRIAL SEPTAL DEFECT CLOSURE. European Cells \& Materials. 2010; 19:158-65. [PubMed: 20408127]

11. Mayer JE Jr. Uses of homograft conduits for right ventricle to pulmonary artery connections in the neonatal period. Semin Thorac Cardiovasc Surg. 1995; 7:130-2. [PubMed: 7548318]

12. Isaka M, Nishibe T, Okuda Y, Saito M, Seno T, Yamashita K, et al. Experimental study on stability of a high-porosity expanded polytetrafluoroethylene graft in dogs. Annals of thoracic and cardiovascular surgery : official journal of the Association of Thoracic and Cardiovascular Surgeons of Asia. 2006; 12:37-41. [PubMed: 16572073]

13. Sacks MS, Chuong CJ. Orthotropic mechanical properties of chemically treated bovine pericardium. Annals of Biomedical Engineering. 1998; 26:892-902. [PubMed: 9779962]

14. Tremblay D, Zigras T, Cartier R, Leduc L, Butany J, Mongrain R, et al. A Comparison of Mechanical Properties of Materials Used in Aortic Arch Reconstruction. Annals of Thoracic Surgery. 2009; 88:1484-91. [PubMed: 19853098]

15. Berry MF, Engler AJ, Woo YJ, Pirolli TJ, Bish LT, Jayasankar V, et al. Mesenchymal stem cell injection after myocardial infarction improves myocardial compliance. American Journal of Physiology-Heart and Circulatory Physiology. 2006; 290:H2196-H203. [PubMed: 16473959]

16. Jacot JG, Martin JC, Hunt DL. Mechanobiology of cardiomyocyte development. Journal of Biomechanics. 2010; 43:93-8. [PubMed: 19819458]

17. Jacot JG, McCulloch AD, Omens JH. Substrate stiffness affects the functional maturation of neonatal rat ventricular myocytes. Biophysical Journal. 2008; 95:3479-87. [PubMed: 18586852]

18. Engler AJ, Carag-Krieger C, Johnson CP, Raab M, Tang H-Y, Speicher DW, et al. Embryonic cardiomyocytes beat best on a matrix with heart-like elasticity: scar-like rigidity inhibits beating. Journal of Cell Science. 2008; 121:3794-802. [PubMed: 18957515]

19. Chi N-H, Yang M-C, Chung T-W, Chen J-Y, Chou N-K, Wang S-S. Cardiac repair achieved by bone marrow mesenchymal stem cells/silk fibroin/hyaluronic acid patches in a rat of myocardial infarction model. Biomaterials. 2012; 33:5541-51. [PubMed: 22575829]

20. Blan NR, Birla RK. Design and fabrication of heart muscle using scaffold-based tissue engineering. J Biomed Mater Res A. 2008; 86:195-208. [PubMed: 17972281]

21. Zein I, Hutmacher DW, Tan KC, Teoh SH. Fused deposition modeling of novel scaffold architectures for tissue engineering applications. Biomaterials. 2002; 23:1169-85. [PubMed: 11791921]

22. Zheng HX, Liu SS, Tian WM, Yan HJ, Zhang Y, Li Y. A three-dimensional in vitro culture model for primary neonatal rat ventricular myocytes. Curr Appl Phys. 2012; 12:826-33.

23. Ren Y-J, Zhou Z-Y, Liu B-F, Xu Q-Y, Cui F-Z. Preparation and characterization of fibroin/ hyaluronic acid composite scaffold. International Journal of Biological Macromolecules. 2009; 44:372-8. [PubMed: 19428469]

24. Sakai T, Li RK, Weisel RD, Mickle DA, Kim ET, Jia ZQ, et al. The fate of a tissue-engineered cardiac graft in the right ventricular outflow tract of the rat. J Thorac Cardiovasc Surg. 2001; 121:932-42. [PubMed: 11326237]

25. van der Giessen WJ, Lincoff AM, Schwartz RS, van Beusekom HM, Serruys PW, Holmes DR Jr, et al. Marked inflammatory sequelae to implantation of biodegradable and nonbiodegradable polymers in porcine coronary arteries. Circulation. 1996; 94:1690-7. [PubMed: 8840862]

26. Li WJ, Cooper JA Jr, Mauck RL, Tuan RS. Fabrication and characterization of six electrospun poly(alpha-hydroxy ester)-based fibrous scaffolds for tissue engineering applications. Acta Biomater. 2006; 2:377-85. [PubMed: 16765878]

27. Htay AS, Teoh SH, Hutmacher DW. Development of perforated microthin poly(epsiloncaprolactone) films as matrices for membrane tissue engineering. J Biomater Sci Polym Ed. 2004; 15:683-700. [PubMed: 15264668]

28. Aliabadi HM, Mahmud A, Sharifabadi AD, Lavasanifar A. Micelles of methoxy poly(ethylene oxide)-b-poly(epsilon-caprolactone) as vehicles for the solubilization and controlled delivery of cyclosporine A. J Control Release. 2005; 104:301-11. [PubMed: 15907581]

29. Pok SW, Wallace KN, Madihally SV. In vitro characterization of polycaprolactone matrices generated in aqueous media. Acta Biomater. 2010; 6:1061-8. [PubMed: 19664731] 
30. Hu M, Kurisawa M, Deng R, Teo C-M, Schumacher A, Thong Y-X, et al. Cell immobilization in gelatin-hydroxyphenylpropionic acid hydrogel fibers. Biomaterials. 2009; 30:3523-31. [PubMed: 19328545]

31. Pok S, Jacot JG. Biomaterials advances in patches for congenital heart defect repair. Journal of cardiovascular translational research. 2011; 4:646-54. [PubMed: 21647794]

32. DeLeon SY, LoCicero J 3rd, Ilbawi MN, Idriss FS. Repeat median sternotomy in pediatrics: experience in 164 consecutive cases. Ann Thorac Surg. 1986; 41:184-8. [PubMed: 3947171]

33. Ozawa T, Mickle DAG, Weisel RD, Koyama N, Wong H, Ozawa S, et al. Histologic changes of nonbiodegradable and biodegradable biomaterials used to repair right ventricular heart defects in rats. J Thorac Cardiovasc Surg. 2002; 124:1157-64. [PubMed: 12447182]

34. Huang Y, Onyeri S, Siewe M, Moshfeghian A, Madihally SV. In vitro characterization of chitosangelatin scaffolds for tissue engineering. Biomaterials. 2005; 26:7616-27. [PubMed: 16005510]

35. Risbud MV, Hardikar AA, Bhat SV, Bhonde RR. pH-sensitive freeze-dried chitosan-polyvinyl pyrrolidone hydrogels as controlled release system for antibiotic delivery. J Control Release. 2000; 68:23-30. [PubMed: 10884576]

36. Ishihara M, Obara K, Nakamura S, Fujita M, Masuoka K, Kanatani Y, et al. Chitosan hydrogel as a drug delivery carrier to control angiogenesis. J Artif Organs. 2006; 9:8-16. [PubMed: 16614797]

37. Tian M, Yang Z, Kuwahara K, Nimni ME, Wan C, Han B. Delivery of demineralized bone matrix powder using a thermogelling chitosan carrier. Acta Biomater. 2012; 8:753-62. [PubMed: 22079781]

38. Kurdi M, Chidiac R, Hoemann C, Zouein F, Zgheib C, Booz GW. Hydrogels as a platform for stem cell delivery to the heart. Congest Heart Fail. 2010; 16:132-5. [PubMed: 20557335]

39. Madihally SV, Matthew HW. Porous chitosan scaffolds for tissue engineering. Biomaterials. 1999; 20:1133-42. [PubMed: 10382829]

40. Sun W, Darling A, Starly B, Nam J. Computer-aided tissue engineering: overview, scope and challenges. Biotechnol Appl Biochem. 2004; 39:29-47. [PubMed: 14563211]

41. Sarasam AR, Krishnaswamy RK, Madihally SV. Blending chitosan with polycaprolactone: effects on physicochemical and antibacterial properties. Biomacromolecules. 2006; 7:1131-8. [PubMed: 16602730]

42. Durst CA, Cuchiara MP, Mansfield EG, West JL, Grande-Allen KJ. Flexural characterization of cell encapsulated PEGDA hydrogels with applications for tissue engineered heart valves. Acta Biomater. 2011; 7:2467-76. [PubMed: 21329770]

43. Maeder MT, Kaye DM. Differential impact of heart rate and blood pressure on outcome in patients with heart failure with reduced versus preserved left ventricular ejection fraction. International journal of cardiology. 2012; 155:249-56. [PubMed: 21035207]

44. Haag UJ, Hess OM, Maier SE, Jakob M, Liu K, Meier D, et al. Left ventricular wall thickness measurements by magnetic resonance: a validation study. The International Journal of Cardiac Imaging. 1991; 7:31-41.

45. Lawrence BJ, Maase EL, Lin HK, Madihally SV. Multilayer composite scaffolds with mechanical properties similar to small intestinal submucosa. Journal Of Biomedical Materials Research Part A. 2009; 88:634-43. [PubMed: 18314898]

46. Grosvenor MP, Staniforth JN. The effect of molecular weight on the rheological and tensile properties of poly(epsilon-caprolactone). International Journal of Pharmaceutics. 1996; 135:103-9.

47. Woodruff MA, Hutmacher DW. The return of a forgotten polymer-Polycaprolactone in the $21 \mathrm{st}$ century. Progress in Polymer Science. 2010; 35:1217-56.

48. Jones DS, Djokic J, McCoy CP, Gorman SP. Poly(epsilon-caprolactone) and poly(epsiloncaprolactone)-polyvinylpyrrolidone-iodine blends as ureteral biomaterials: characterisation of mechanical and surface properties, degradation and resistance to encrustation in vitro. Biomaterials. 2002; 23:4449-58. [PubMed: 12322963]

49. Filipe, DVMN.; Murphy, MK.; Singh, DA. Design of a Composite Scaffold for Myocardial Regeneration Following Infarction. Worcester Polytechnic Institute; 2007.

50. Cheng MY, Deng JU, Yang F, Gong YD, Zhao NM, Zhang XF. Study on physical properties and nerve cell affinity of composite films from chitosan and gelatin solutions. Biomaterials. 2003; 24:2871-80. [PubMed: 12742725] 
51. Yin YJ, Yao KD, Cheng GX, Ma JB. Properties of polyelectrolyte complex films of chitosan and gelatin. Polymer International. 1999; 48:429-32.

52. Thein-Han WW, Saikhun J, Pholpramoo C, Misra RDK, Kitiyanant Y. Chitosan-gelatin scaffolds for tissue engineering: Physico-chemical properties and biological response of buffalo embryonic stem cells and transfectant of GFP-buffalo embryonic stem cells. Acta Biomater. 2009; 5:3453-66. [PubMed: 19460465] 


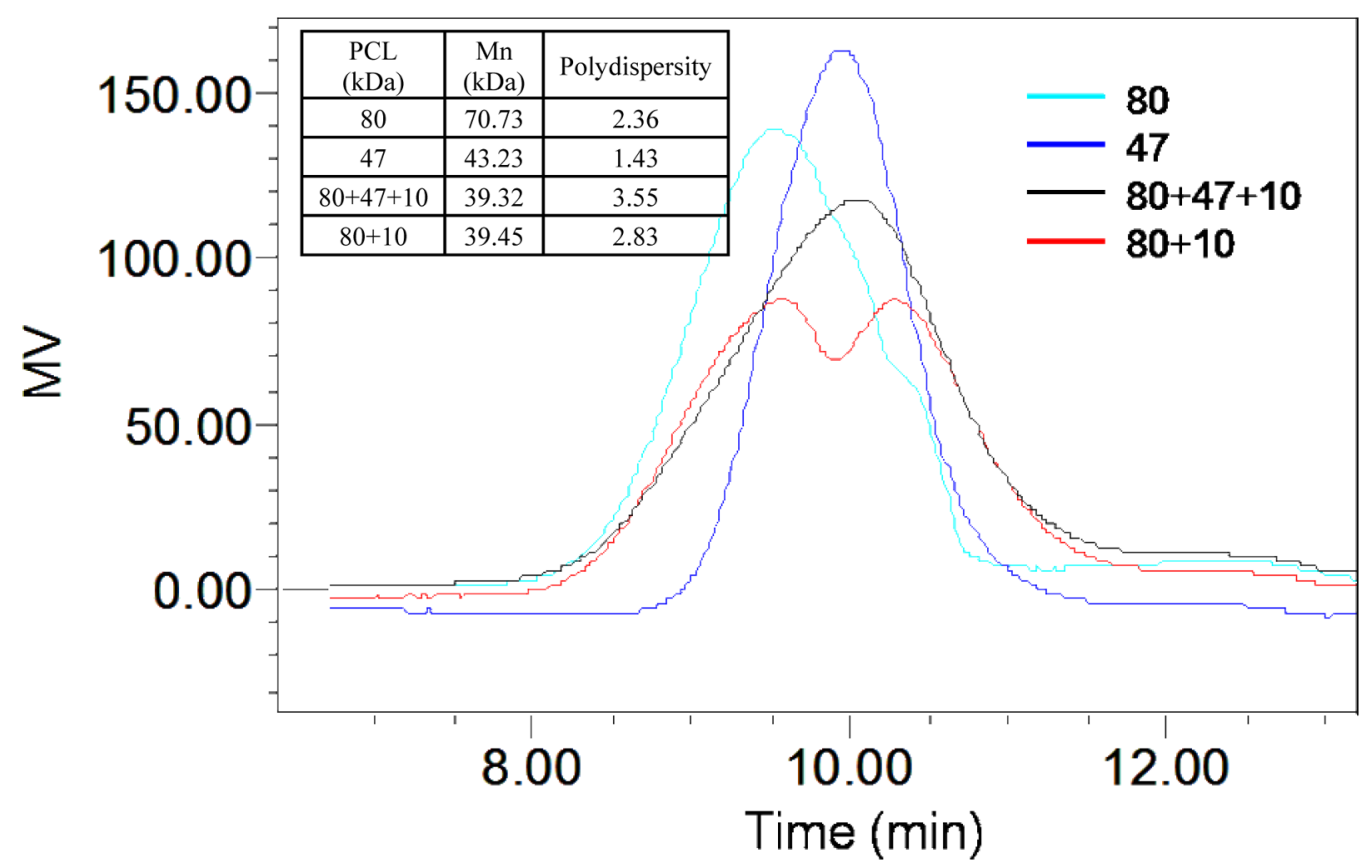

Figure 1.

Liquid chromatographic analysis of components shows that all components are retained in formed PCL matrices, with two Mn peaks visible in $80+10 \mathrm{kDa}$ blended matrices. Inset shows the average molecular weight and polydispersity index for pure and blended self assembled PCL matrices. The $\mathrm{x}$-axis of Figure 1 shows the retention times of the gel permeation chromatography assay, and these are proportional to the polymer molecular weight. Matrices crystallized from single Mn PCL have single peaks, while the matrix crystalized from a blend of equal amounts of 80 and $47 \mathrm{kDa}$ PCL has equal peaks resulting from the two separate polymer molecular weights, as expected. The polydispersity index is the ratio of the mass average molecular weight to the number average molecular weight, and gives an indication of the heterogeneity of the polymer. The polydispersity indices measured for all single Mn matrices were higher than those indicated by the manufacturer, and the molecular weights were lower, indicating some degradation in processing. 

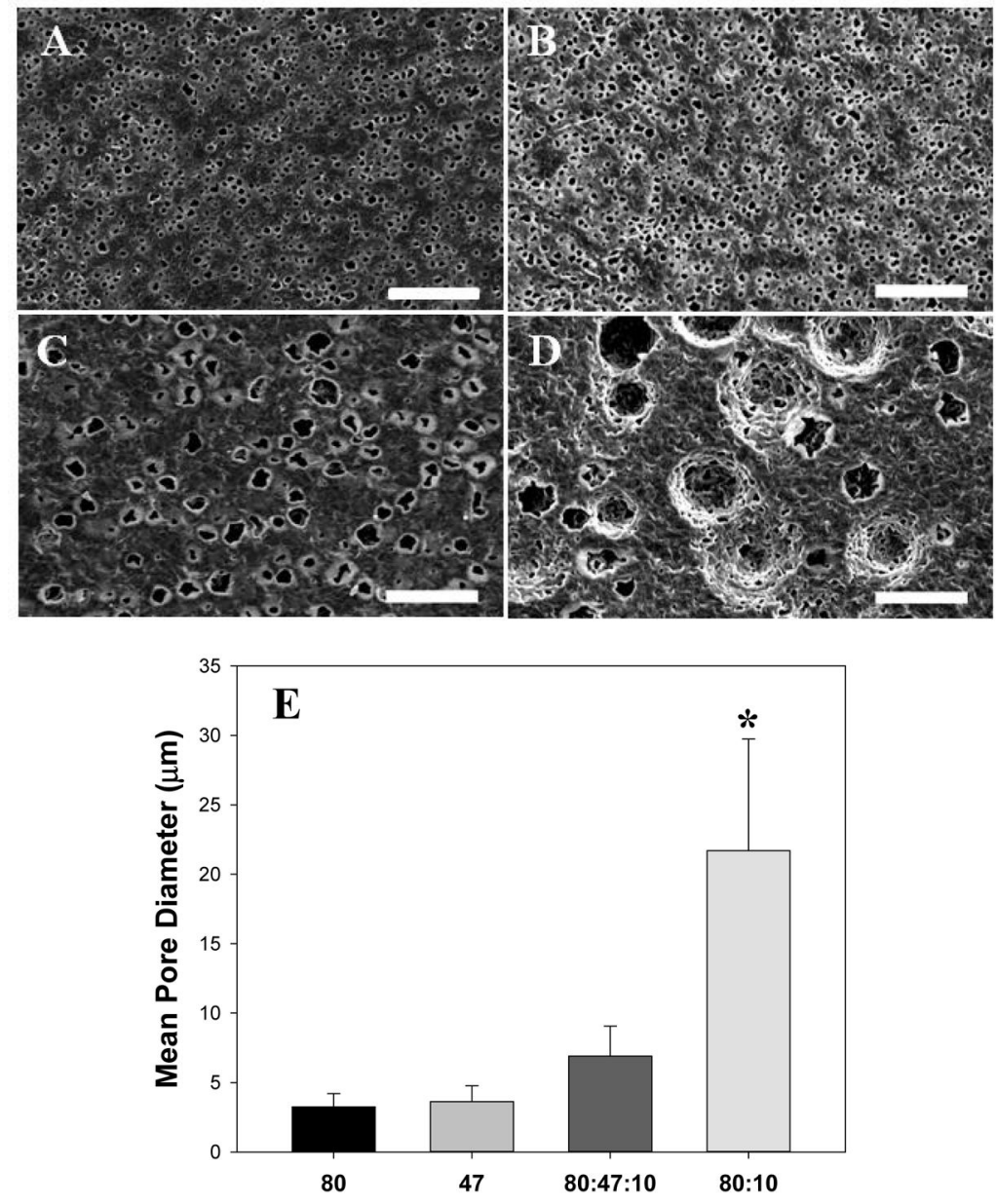

Figure 2. Representative SEM micrographs and mean pore diameters of self-assembled PCL with different Mn

(A-D) SEM shows perforations and micro-domains in 80+10 KDa gels that are not present in other self-assembled PCL scaffolds with various $\mathrm{Mn}$ and blending ratios (A: $80 \mathrm{kDa} ; \mathrm{B}$ : $47 \mathrm{kDa}$; C: $80+47+10 \mathrm{kDa}$; D: $80+10 \mathrm{kDa}$ ). Scale bars are $50 \mu \mathrm{m}$. (E) The mean pore diameter of $80+10 \mathrm{kDa}$ sample was significantly larger than all other blends $(* ; \mathrm{p}<0.05$, $\mathrm{n}=6)$. 

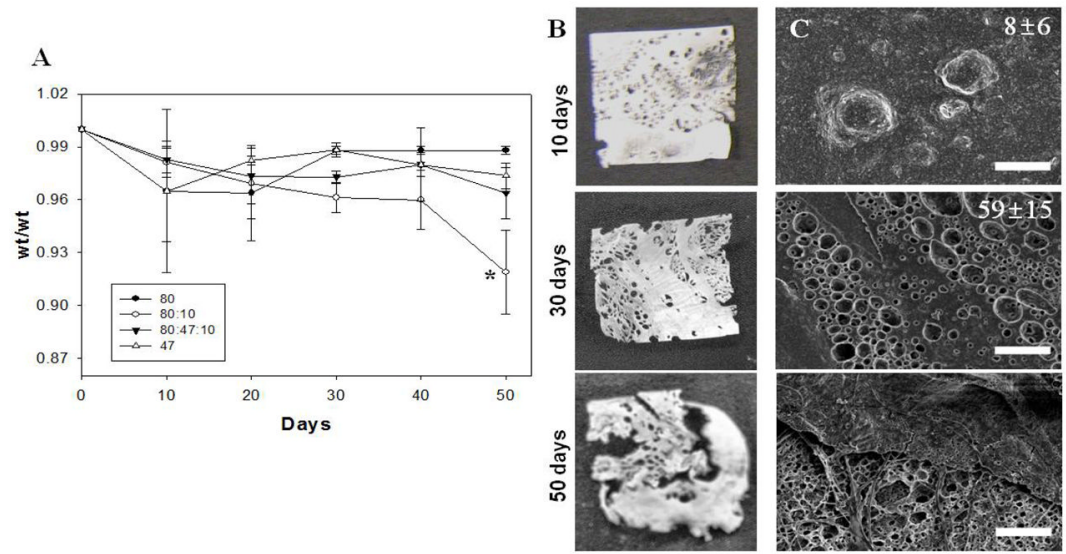

Figure 3. Altered degradation rate by blending of different Mn

(A) Degradation rates of PCL scaffolds at various blending ratios of $80 \mathrm{kDa}, 47 \mathrm{kDa}$ and 10 $\mathrm{kDa}$ PCL, incubated in Krebs-Henseleit buffer solutions. Note that the $80+10 \mathrm{kDa}$ blended PCL scaffold showed $\sim 10 \%$ of weight loss after 50 days where as others had less than $5 \%$ of weight loss (*; p<0.05, n=4). (B) Macroscopic images of $80 \mathrm{kDa}+10 \mathrm{kDa}$ PCL scaffold $(15 \times 15 \mathrm{~mm})$ after incubation in buffer solution. (C) SEM micrographs of $80 \mathrm{kDa}+10 \mathrm{kDa}$ PCL scaffold after incubation in buffer solution. Numbers on the Figure $\mathrm{C}$ indicate the number of pores $(>10 \mu \mathrm{m}$ in diameter) on $200 \times 200 \mu \mathrm{m}$ dimension. Scale bars are $50 \mu \mathrm{m}$. 

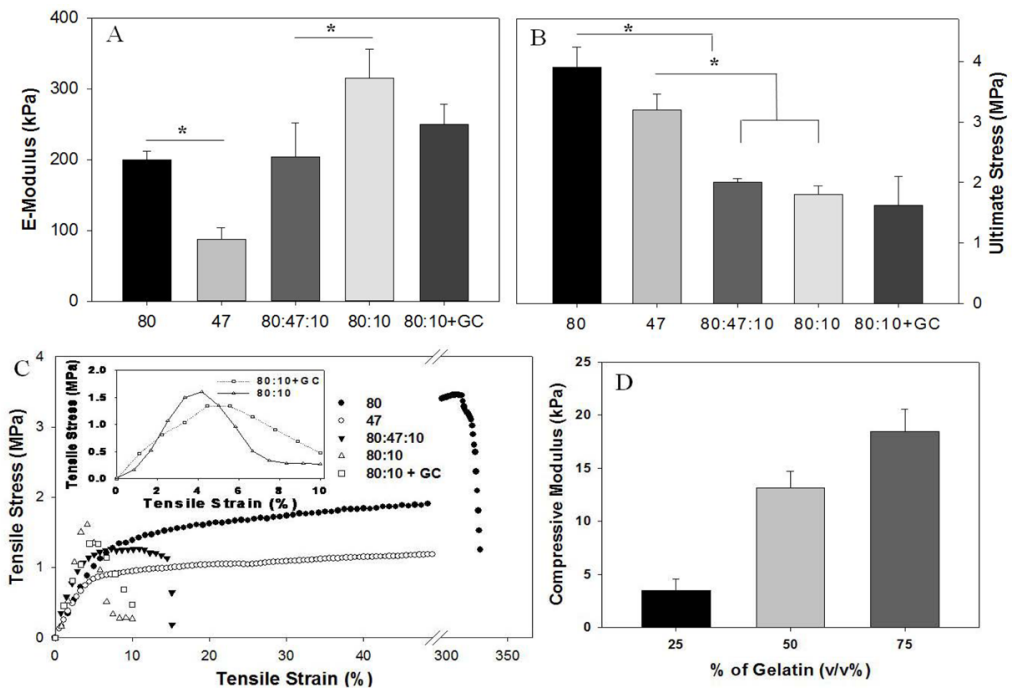

Figure 4. Mechanical properties of PCL matrices and gelatin-chitosan-PCL multi-layered scaffolds

(A) The tensile elastic modulus of various Mn PCL matrices and PCL-GC multilayered scaffolds (*; $\mathrm{p}<0.05 ; \mathrm{n}=5)$. PCL-GC multi-layered scaffolds was not significantly different than $80+10$ kDa PCL matrices alone. $(p=0.178$; $n=5)$. (B) The ultimate tensile stress significantly decreased with PCL molecular weight and decreases in blended matrices (*; $\mathrm{p}<0.05 ; \mathrm{n}=5)$. The ultimate tensile strength of PCL-GC multi-layered scaffolds was not significantly different than $80+10 \mathrm{kDa}$ PCL matrices alone $(\mathrm{p}=0.499 ; \mathrm{n}=4)$. (C) Representative tensile stress-strain curves from various Mn PCL matrices and PCL-GC multi-layered scaffolds. Inset shows tensile stress-strain curves of 80+10 kDa PCL matrices and multi-layered PCL-GC scaffolds. (D) The compressive modulus of multi-layered PCLGC scaffolds increased with increasing gelatin concentration $(* ; \mathrm{p}<0.01 ; \mathrm{n}=4)$. 

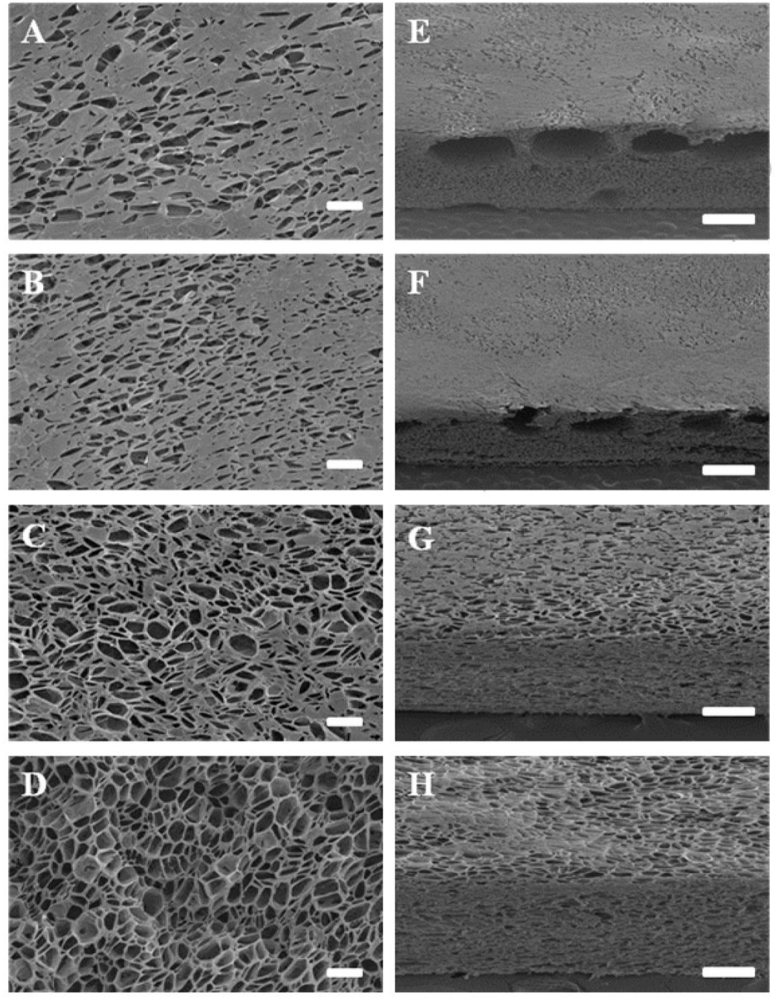

Figure 5. Microscopic structure of multi-layered hydrogels

(A-D) SEM micrographs of multi-layered scaffolds with different blending ratios of gelatin:chitosan (v:v). (A - 0:100; B - 25:75; C - 50:50; D - 75:25) and (E-H) 3-D view of multi-layered scaffolds $(E-0: 100 ; \mathrm{F}-25: 75 ; \mathrm{G}-50: 50 ; \mathrm{H}-75: 25)$. All samples formed a 3 -D porous structure after lyophilization. Scaffolds with $50 \%$ or greater gelatin concentrations had hive-like structures and elliptical pores. Scale bars are $100 \mu \mathrm{m}$. 

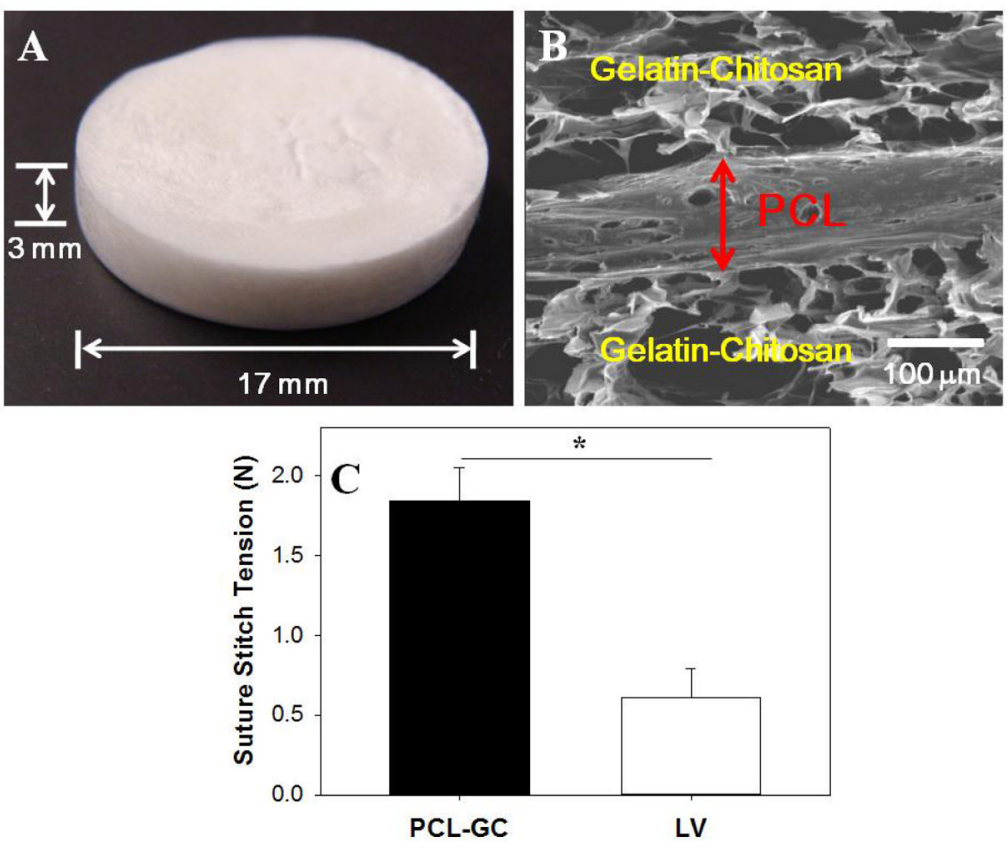

Figure 6. Macroscopic and microscopic structure and the ultimate suture force of multilayered hydrogels

(A) Multi-layered scaffolds were formed in disk shapes with an $80+10 \mathrm{kDa}$ PCL core sandwiched in a gelatin-chitosan hydrogel. (B) An SEM micrograph of a cross-sectional view shows that the hydrogel attached to the both sides of 80:10 kDa PCL matrix and adhered through perforations. (C) The average ultimate force of a suture in the multi-layered scaffold is significantly higher than estimated tension on a suture of a full-thickness patch in a human LV with $138 \pm 19 \mathrm{mmHg}$ of peak systolic pressure $(* ; \mathrm{p}<0.001, \mathrm{n}=5)$. 

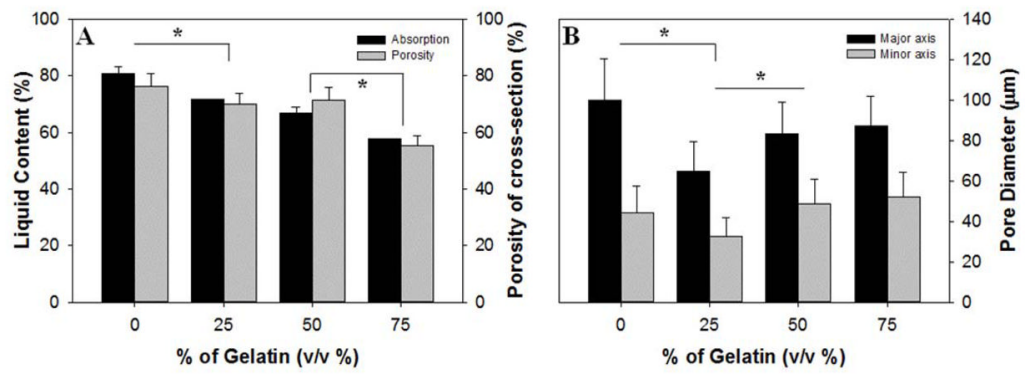

Figure 7. Porous characteristics of multi-layered hydrogels

(A) The water content decreased from $\sim 80 \%$ to $\sim 60 \%$ by increasing $\%$ of gelatin from 0 to $75 \%$. The porosity also decreased from $\sim 75 \%$ to $\sim 55 \%$ by increasing $\%$ of gelatin from 0 to $75 \%$. (B) Pure chitosan had larger mean pore diameters in both the major and minor axes compared to pore diameters of scaffolds formed with $25 \%$ gelatin. However, the mean pore sizes increased significantly with increasing gelatin $(*: p<0.05 ; n=20)$. There was no significant difference between 50 and $75 \%$ gelatin gels $(p=0.655, n=5)$. 

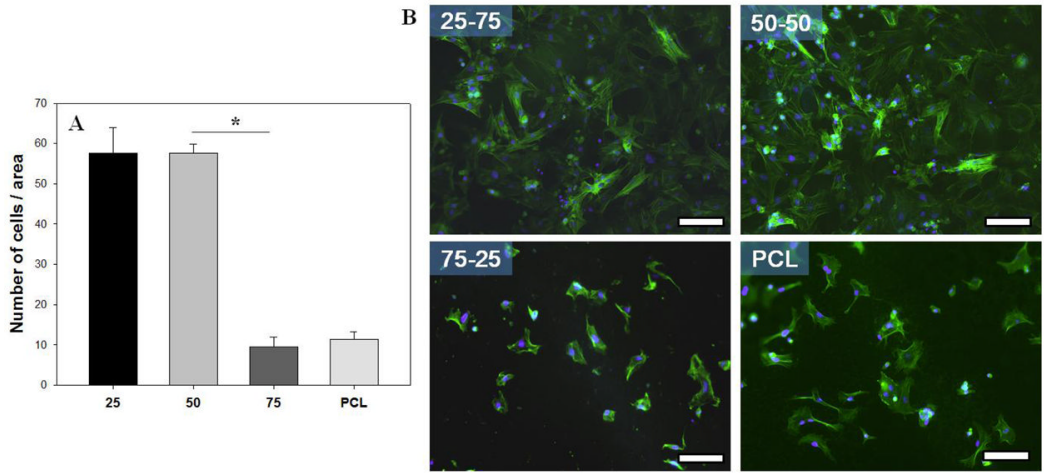

Figure 8. Attachment and morphology of NRVM on multi-layered scaffolds

(A) Multilayered scaffolds with $25 \%$ and $50 \%$ gelatin had significantly more cells attached than scaffolds with $75 \%$ gelatin or uncoated PCL $\left(\sim 57\right.$ cells $/ 0.1 \mathrm{~mm}^{2}$ for 25 and $50 \%$ vs. $\sim 10$ cells $/ 0.1 \mathrm{~mm}^{2}$ for $75 \%$ and uncoated; PCL $* \mathrm{P}<.005 ; \mathrm{n}=6$; area $=0.1 \mathrm{~mm}^{2}$ ) (B) NRVM stained for f-actin (FITC-phalloidin, green) and DNA (DAPI, blue) after 5 days reveal highly spread, interconnected cells on scaffolds with $50 \%$ collagen. Scale bars are $100 \mu \mathrm{m}$. 


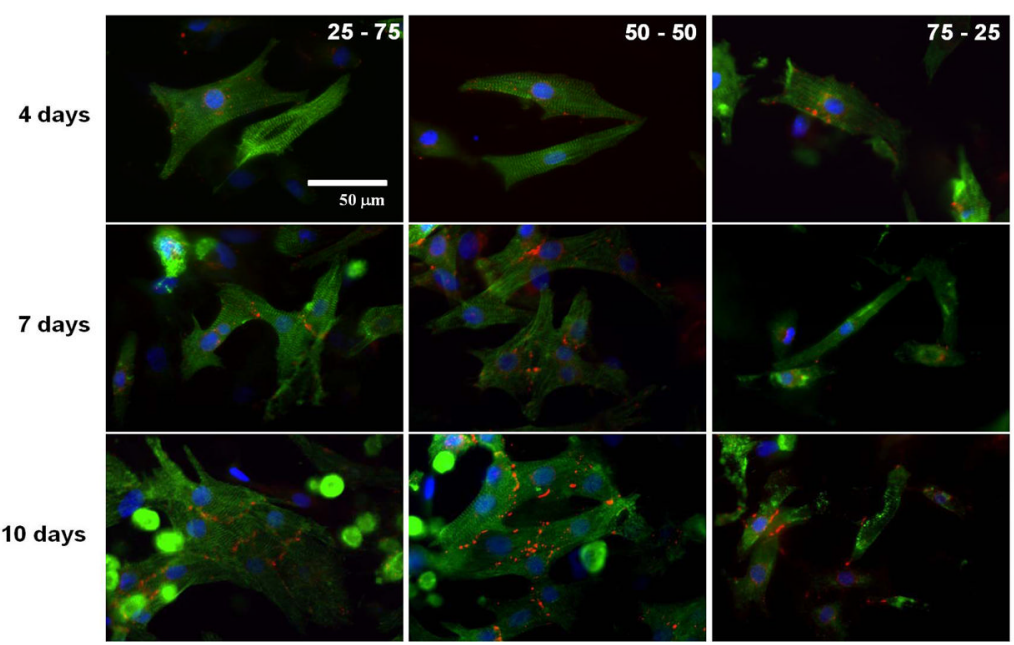

Figure 9. NRVM morphology on the multi-layered scaffolds

NRVM stained for sarcomeres (Anti- a-actinin, green), gap junction (Anti-connexin-43, red) and DNA (DAPI, blue) after 4,7, and 10 days in culture. Samples with $25 \%$ and 50\% gelatin (by volume) had much greater cell spreading, aligned sarcomeres and interconnectivity. Scale bars are $50 \mu \mathrm{m}$. 

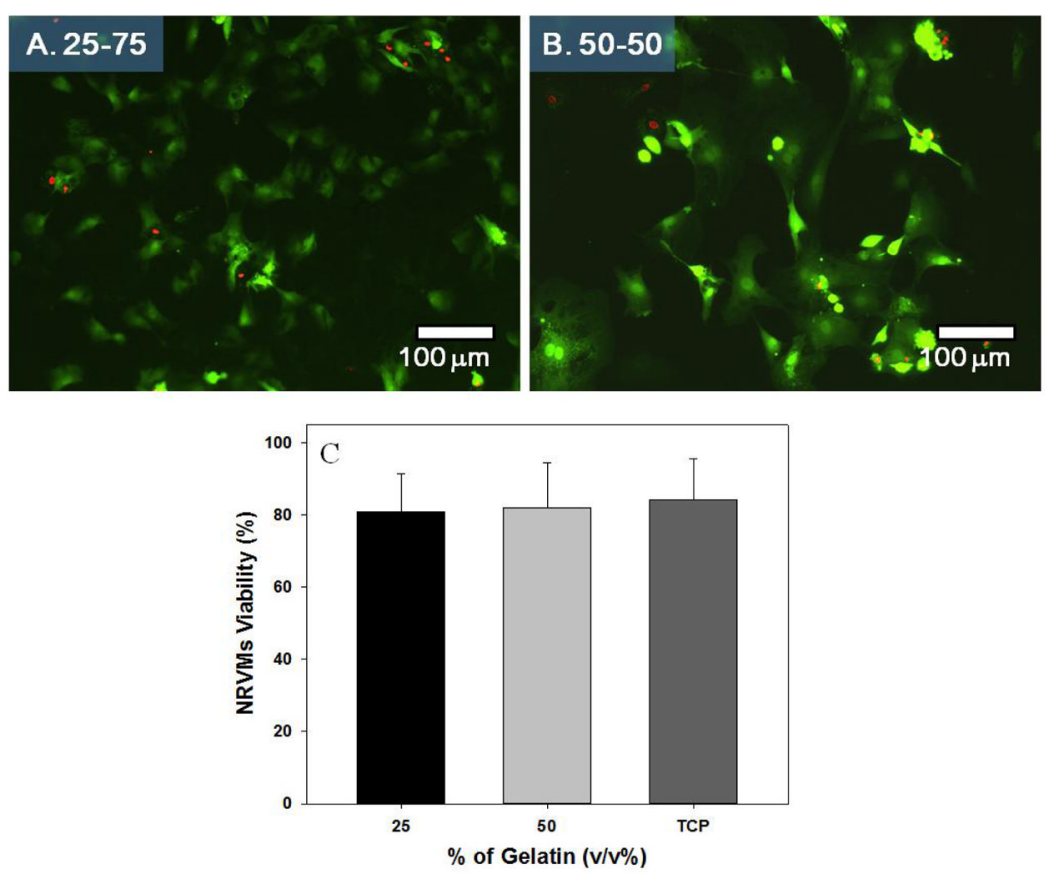

Figure 10. Viability of NRVMs plated on multi-layered hydrogels.)

Live cells were retained with green fluorescence by polyanionic dye calcein, and dead cells with red fluorescence were stained with EthD-1 after 4 days in samples of (A) $25 \%$ gelatin and $75 \%$ chitosan and (B) 50\% gelatin and 50\% chitosan. (C) Both 25 and $50 \%$ gelatin samples showed high cell viability $\sim 80 \%$ on the surface of hydrogels. There is no significant difference of cell viability between cells seeded on hydrogels and tissue culture plastic $(\mathrm{TCP})(\mathrm{P}=0.876 ; \mathrm{n}=3)$. 

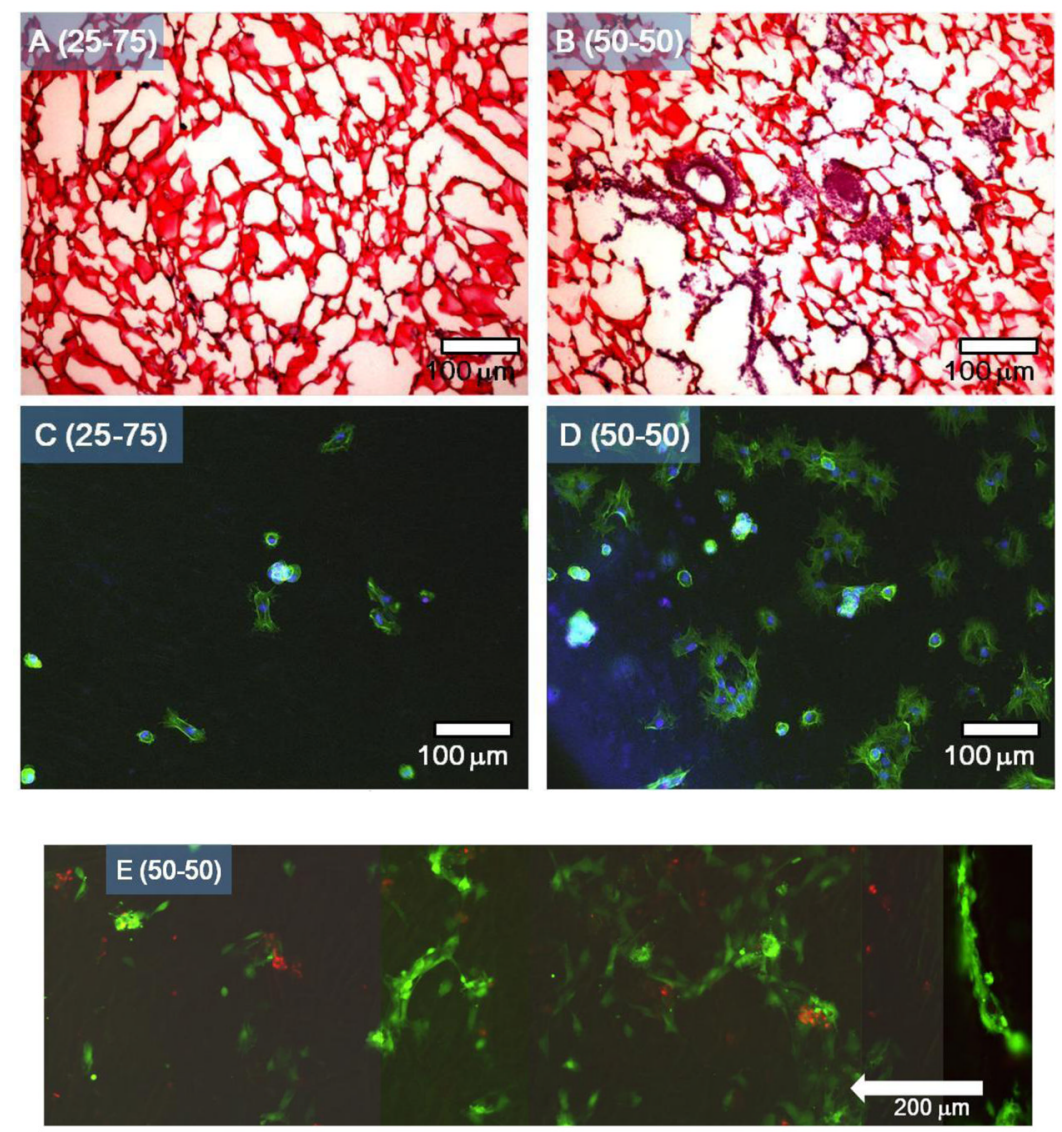

Figure 11. Micrographs of sectioned multi-layered hydrogels

Sectioned samples were (A,B) stained for the cell nucleus (haematoxylin, black) and protein (with eosin, red) and (C,D) for f-actin (FITC-phalloidin, green) and the nucleus (DAPI, blue) after 10 days. The $50 \%$ gelatin- $50 \%$ chitosan scaffolds had more cells in the scaffold and showed high NRVM interconnectivity compared to the $25 \%$ gelatin- $75 \%$ chitosan scaffolds (E) A cross-sectional view of 50\% gelatin-50\% chitosan scaffold is shown from 5 overlapping figures, and reveals fewer cells and more dead cells with increasing depth from the plated top surface (right edge). 